\title{
INSTALASI DAN KONFIGURASI SERVER DALAM SATU PERANGKAT KOMPUTER SEBAGAI MEDIA PEMBELAJARAN ALTERNATIF
}

\author{
Ahmad Roihan ${ }^{1}$ \\ Moch. Indra Irawan ${ }^{2}$ \\ Karwandi ${ }^{3}$ \\ ${ }^{1}$ Perguruan Tinggi Raharj ,2 SMKN 10 Kab. Tangerang, ${ }^{3}$ SMK Pustek Serpong \\ Email : ahmad.roihan@raharja.info ${ }^{1}$,indrapossible@gmail.com ${ }^{2}$,caronedie@ymail.com ${ }^{3}$
}

\begin{abstract}
Computer network consists from computer server and computer client. To learn it must have a minimum of two computer devices. To make this easier, virtualization is the proper technique to learn computer network. By installing an application of virtual machine, one computer can install multiple operating systems. One operating system installed for client as default system and other installed as server, until both of them can communicate each other. This technique is an advantage for alternatif learning.
\end{abstract}

Keyword: network, server, client, virtualization

\begin{abstract}
ABSTRAKSI
Jaringan komputer dalam suatu perusahaan biasanya terdiri dari komputer server dan beberapa komputer klien. Fungsi dari komputer server adalah sebagai media penyedia layanan untuk komputer klien, sehingga seluruh komputer klien dapat saling berkomunikasi dan berbagi data baik dari klien ke server ataupun sebaliknya. Dalam perihal pembelajaran komputer klien server metode dengan menggunakan dua perangkat komputer sangat membutuhkan banyak komputer, sehingga metode ini sangat kurang efektif dan efisien. Oleh karena digunakanlah teknik virtualisasi sebagai media pembelajaran jaringan alternatif.
\end{abstract}

Kata Kunci: jaringan, server, klien, virtualisasi

\section{PENDAHULUAN}

Server adalah perangkat jaringan yang memberikan layanan terhadap pengguna. Server melayani pengguna dengan handal dan harus bisa melakukanya setiap saat. Maka analisa terhadap kebutuhan server untuk bisa memenuhi tugasnya sangat dibutuhkan. Server yang lemah, tidak sesuai, dan tidak handal, bisa membuat kerugian yang besar. Oleh karena itu, ada beberapa faktor yang harus dipertimbangkan sebelum membuat sebuah server (Antonius Duty Susilo, 2013: 20).

Sistem operasi (operating system atau OS) adalah perangkat lunak yang bertugas untuk mengatur, mengendalikan perangkat keras dan memberikan kemudahan untuk pemakai dalam penggunaan komputer. Sistem operasi akan melakukan layanan inti umum untuk software aplikasi. Layanan tersebut seperti akses ke disk, manajemen memori, tugas penjadwalan, dan antar-muka user. Bagian kode yang melakukan tugastugas ini dinamakan dengan "kernel" suatu sistem operasi (Abdul Munif, 2013: 8). Perangkat lunak adalah obyek tertentu yang dapat dijalankan seperti kode sumber, kode obyek, atau sebuah program yang lengkap. Produk perangkat lunak memiliki pengertian perangkat lunak yang ditambahkan dengan semua item dan pelayanan pendukung yang secara keseluruhan dapat memenuhi kebutuhan pemakai. Produk perangkat lunak memiliki banyak bagian yang meliputi manual, referensi, tutorial, instruksi instalasi, data sampel, pelayanan pendidikan, pelayanan pendukung teknis dan sebagainya (Al-Bahra Bin Ladjamuddin B, 2006: 3).

Sistem Operasi Close Source (Proprietari) merupakan sistem operasi yang dikembangkan secara internal oleh seseorang, 
perkumpulan ataupun perusahaan. Sistem operasi yang tergolong proprietari ini adalah Windows dan Mac Os. Sistem Operasi Open Source (Terbuka) merupakan sistem operasi yang kode programnya dibuka untuk umum sehingga dapat dikembangkan oleh yang lainnya. Sistem operasi yang termasuk terbuka adalah UNIX, Linux dan turunannya. Linux sendiri memiliki banyak varian, seperti Debian, Slackware, Redhat dan SuSE. Varian ini lebih dikenal dengan nama distro (Kadek Surya Pranata, 2013:31).

Instalasi merupakan hal yang paling awal dilakukan sebelum membangun server. Instalasi ini mencakup dua hal, instalasi perangkat keras dan perangkat lunak. Sebagai server yang akan melayani komunikasi antar jaringan, maka sebuah server minimal harus memiliki 2 kartu jaringan. Satu untuk jaringan internal dan lainnya untuk jaringan eksternal. Instalasi sistem operasi server hampir sama dengan instalasi sistem operasi biasa. Yaitu dengan cara menentukan lokasi instalasi, memilih alokasi partisi, menentukan informasi akun utama (root), dan menentukan informasi tentang server.

Berawal dari eksperimen Linus Trovalds dengan Komputer Minix miliknya, terciptalah sistem operasi Linux. Sejak saat itu, Dia terus mengembangkan dan memperbaiki sistem operasi temuannya tersebut. Berkat kerja kerasnya, terciptalah Linux 1.0 yang keseluruhanya berbasis TEKS. Karena Linux bersifat Open Source, dan dengan cepatnya Sistem Informasi \& Komunikasi saat ini, Linux telah berkembang begitu pesat. Sampai saat ini, sudah tak terhitung lagi, berapa banyak distro-distro yang sudah dikembangkan. Dari Linux yang berbasis TEKS, berkembang menjadi Linux yang berbasis GRAFIK. Bahkan tampilannya pun telah dapat menyaingi Sistem Operasi berbayar sekali pun (Pudja Mansyurin, 2011:6). Debian adalah sistem operasi open source dan bebas di bawah lisensi GNU (GNU's Not Unix), sistem operasi berbasis Unix dapat digunakan sebagai sistem operasi desktop maupun server. Debian dikembangkan oleh para programmer relawan dari seluruh seluruh dunia atas dasar pengembangan terbuka (open source) untuk dilakukan berbagai penambahan fungsi dan fitur baru pada setiap rilis versi terbarunya. Pengembangan Debian juga didukung oleh sumbangan melalui SPI (Software in the
Public Interest), yaitu sebuah organisasi non profit untuk proyek-proyek open source (http://www.spi-inc.org/).

Arsitektur server sederhana, yang mana server terdiri dari 2 komponen utama, yaitu software dan hardware. Software terdiri dari sistem operasi, sistem operasi bisa menampung aplikasi-aplikasi web server, DNS server, DHCP server, dll. Hardware menampung perangkat-perangkat keras di mesin server. Fitur-fitur yang biasa didukung oleh sistem operasi server, yang bisa dipasang didalamnya adalah seperti aplikasi untuk berbagi file dan printer, layanan database, web, perpesanan, atau terminal (Antonius Duty Susilo, 2013: 55).

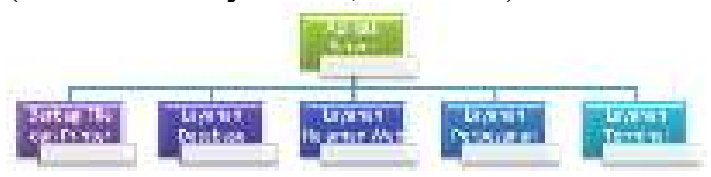

Gambar 1. Fitur Sistem Operasi Server

Jaringan komputer adalah beberapa peranti keras (komputer) independen yang terhubung melalui media transmisi dengan aturan/protokol tertentu sehingga dapat saling berkomunikasi satu sama lainnya seperti chatting, berkirim e-mail, berbagi data dan peranti keras (printer, hard disk, dan prosesor). Prinsip dasar jaringan adalah pross pengiriman data dari pengirim ke penerima melalui suatu media komunikasi tertentu. (Andi Novianto, Muh. Kasmadi, Sidik Pramono, 2012: 7)

Sistem operasi Debian merupakan sistem operasi berbasis jaringan yang sering disebut sistem operasi untuk komputer server, maka dalam mempelajari ataupun mengkonfigurasikan sistem operasi ini harus ada minimal satu komputer untuk dijadikan server dan satu komputer untuk dijadikan klien. Oleh karena itu muncul suatu permasalahan bila ingin mempelajari sistem operasi ini jika hanya memiliki satu komputer.

\section{PERMASALAHAN}

Berdasarkan latar belakang di atas, maka permasalahan yang muncul adalah bagaimana caranya mengkonfigurasikan satu komputer dijadikan media pembelajaran yang efektif dan efisien dalam mempelajari dan mengkonfigurasi sistem operasi Debian ini. 


\section{CRITICAL REVIEW}

Virtualisasi merupakan teknik yang memungkinkan instalasi sistem operasi dilakukan di atas sistem operasi yang ada. Tidak dalam partisi tertentu namun dalam suatu file tertentu. File ini merupakan perwakilan dari suatu sistem komputer virtual. Satu komputer dapat memiliki lebih dari satu komputer virtual. Oleh karena itu, instalasi lebih dari satu sistem operasi juga dimungkinkan dengan teknik ini. Beberapa aplikasi yang memungkinkan untuk membuat sistem virtual ini adalah VirtualBox, VMWare, dan Virtual PC (Kadek Surya Pranata, 2013: 48).

Oracle VM VirtualBox adalah perangkat lunak virtualisasi, yang dapat digunakan untuk mengeksekusi sistem operasi "tambahan" di dalam sistem operasi "utama". Sebagai contoh, jika seseorang mempunyai sistem operasi MS Windows yang terpasang di komputernya, maka seseorang tersebut dapat pula menjalankan sistem operasi lain yang diinginkan di dalam sistem operasi MS Windows (Wikipedia: VirtualBox).

\section{PEMECAHAN MASALAH}

Dalam penulisan artikel ini digunakan beberapa metode penyelesaian masalah SDLC melalui empat tahapan sebagai berikut:

a. Planning:

- Menentukan aplikasi yang dapat membuat virtualisasi sistem operasi dalam satu perangkat komputer.

- Memilih perangkat keras dan sistem operasi server.

b. Analisis:

- Membandingkan teknik sebelumnya yaitu teknik yang menggunakan dua perangkat komputer dengan teknik virtualisasi.

- Konfigurasi dapat dilakukan sehingga antara sistem operasi server dan klien dapat saling berkomunikasi.

c. Desain:

- Perancangan dilakukan dengan mesin virtual yang bernama VirtualBox.

d. Implementasi:

- Implementasi dilakukan dengan cara menghubungkan jaringan antara sistem operasi asli dengan sistem operasi virtual.

\section{IMPLEMENTASI DAN PEMBAHASAN}

Dalam implementasi, artikel ini menuliskan bahwa instalasi aplikasi mesin virtual di dalam sistem operasi dengan menggunakan VirtualBox, dikarenakan VirtualBox merupakan mesin virtual yang berbasis terbuka untuk umum (free) dan dapat diunduh di internet. Setelah instalasi VirtualBox selesai, maka akan muncul tampilan sebagai berikut,

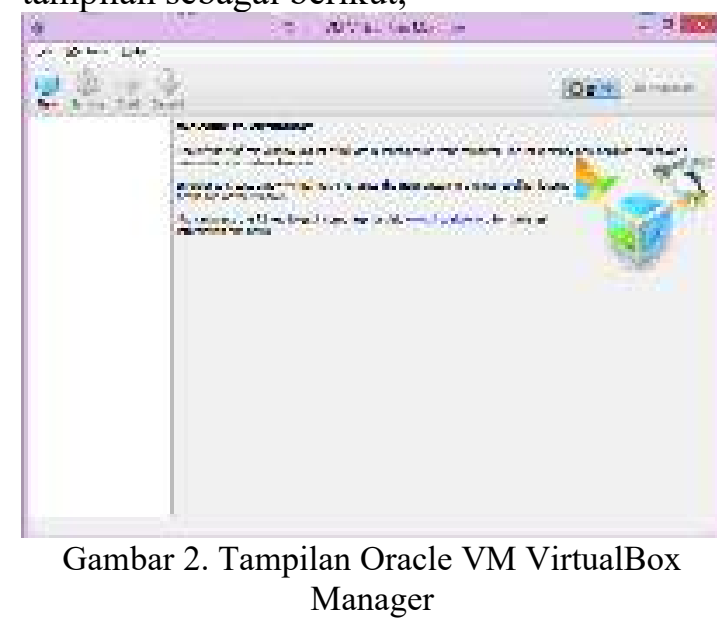

Penambahan disc image sistem operasi Debian dilakukan untuk memulai instalasi sistem operasi baru di dalam sistem operasi yang telah ada. Kemudian konfigurasi kapasitas memory pada sistem operasi Debian yang nanti akan muncul sebagai sistem operasi baru, lalu membuat tipe hard drive, status penyimpanannya, dan kapasitas hard drive yang akan digunakan. Sehingga muncul sistem operasi yang akan dilakukan instalasi dan konfigurasi.

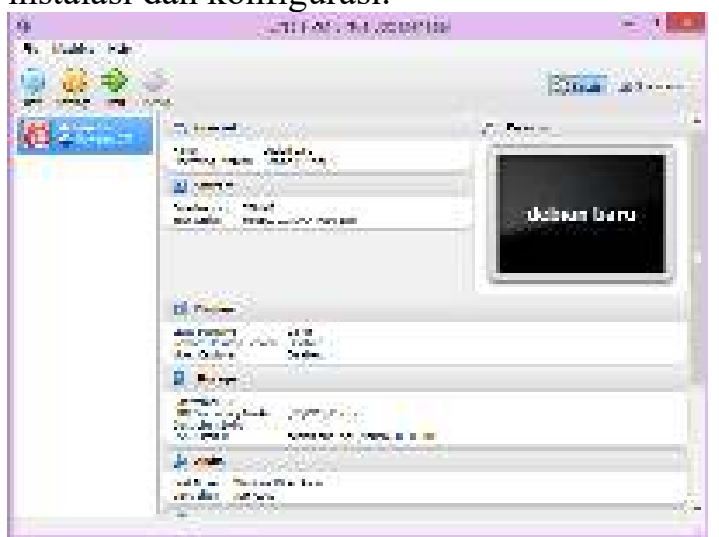

Gambar 3. Tampilan Penambahan Debian di VirtualBox 
Dalam memulai instalasi Debian satu hal yang harus diperhatikan agar sistem jaringan ini terbentuk dan dapat saling berkomunikasi antara sistem operasi yang nanti akan diinstall dengan sistem operasi yang sudah ada, yaitu dengan cara mengkonfigurasi network.

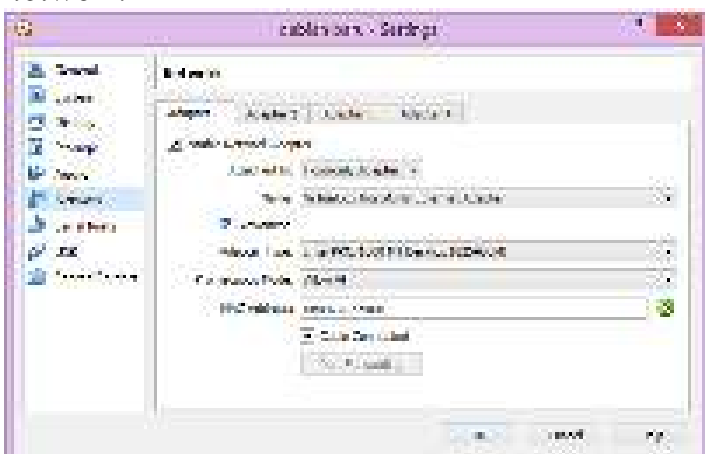

Gambar 4. Tampilan Setting Network di VirtualBox

Setelah mesin virtual telah dikonfigurasi dengan baik, hal selanjutnya yang akan dilakukan yaitu memulai instalasi sistem operasi Debian dimulai dari pemilihan tipe Debian yang berbasis Command Line Interface atau Graphical User Interface sampai akhir instalasi hingga muncul finish the installation.

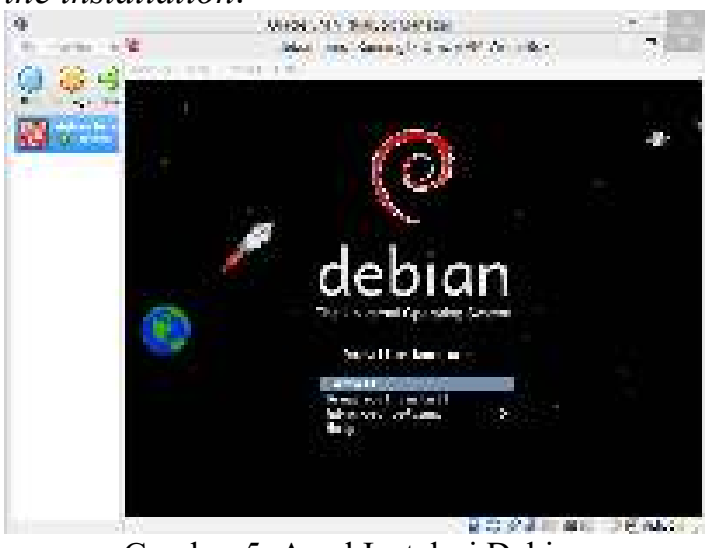

Gambar 5. Awal Instalasi Debian

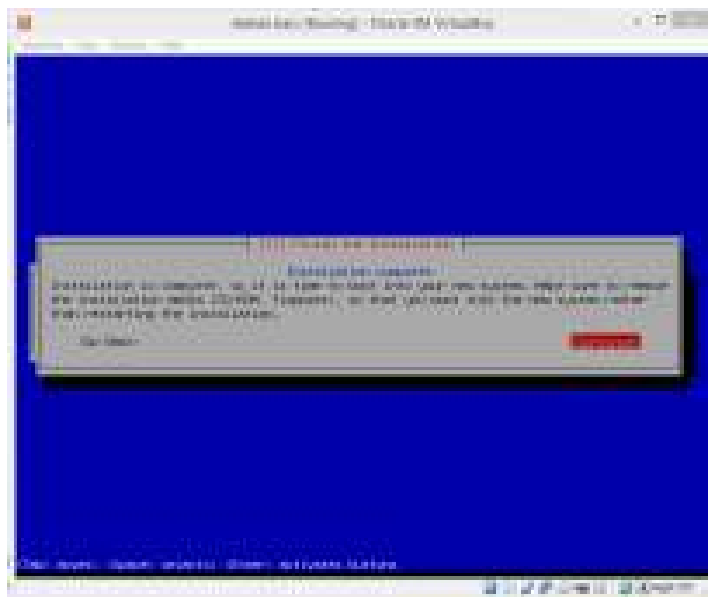

\section{Gambar 6. Akhir Instalasi Debian}

Instalasi sistem operasi Debian sudah selesai. Pengujian antara komputer server (Debian) dan komputer klien dapat dilakukan dengan berbagai macam teknik komunikasi, yaitu FTP Server, DNS Server, DHCP Server, Web atau HTTP Server, Mail Server, Webmail, Remote Server, NTP Server, Proxy Server, Samba Server, VPN Server, Multimedia Streaming Server. Untuk memperkuat bahwa kedua sistem operasi ini dapat saling berkomunikasi, pada artikel ini percobaan pengujian dilakukan dengan dua cara teknik komunikasi yaitu Web Server dan Samba Server.

\section{a. Pengujian dengan Web Server}

HTTP server atau Web server adalah sebuah layanan yang menyediakan akses ke sumber daya dengan menggunakan protokol HTTP. Sumber daya HTTP biasanya berupa dokumen $H T M L$, dilengkapi juga dengan dokumen beformat lainya yang mendukung $H T M L$. Secara default, HTTP server berjalan di atas port 80 untuk versi normal, dan berjalan di atas port 443 untuk versi aman atau HTTPS.

HTTPS berjalan di atas enkripsi data sehingga data yang dikirimkan aman dan tidak bisa dicuri ditengah jalan (Antonius Duty Susilo, 2013: 215). Tahap pertama kali dalam pengujian ini, yaitu instalasi terlebih dahulu keperluan untuk aplikasi Web Server yang bernama apache2, dengan cara mengetik:

root@debian \# apt-get install apache2

Satu hal yang paling utama dalam instalasi aplikasi yaitu pastikan logo CD pada VirtualBox hidup dan terkoneksi ke image file dari Debian karena instalasi sistem operasi ini akan memanggil package yang dibutuhkan dalam proses instalasi Debian. Sistem akan memanggil kemana saja termasuk mirror network (internet) dan $\mathrm{CD} /$ DVD, sampai sistem mendapatkan sesuai dengan perintah yang diketik oleh pengguna. 


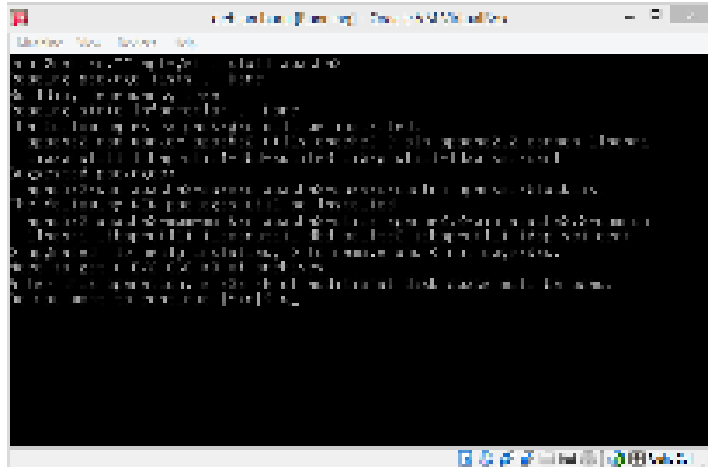

Gambar 7. Proses Instalasi Web Server

Setelah instalasi Apache2 selesai, pengujian sebenarnya dapat langsung dilakukan yaitu dengan melihat ip address dari sistem operasi Debian dengan cara mengetik:

root@debian \# ifconfig

Lalu masukkan ip address dari server Debian ke dalam alamat browser di sistem operasi klien, seperti gambar 8 di bawah ini,

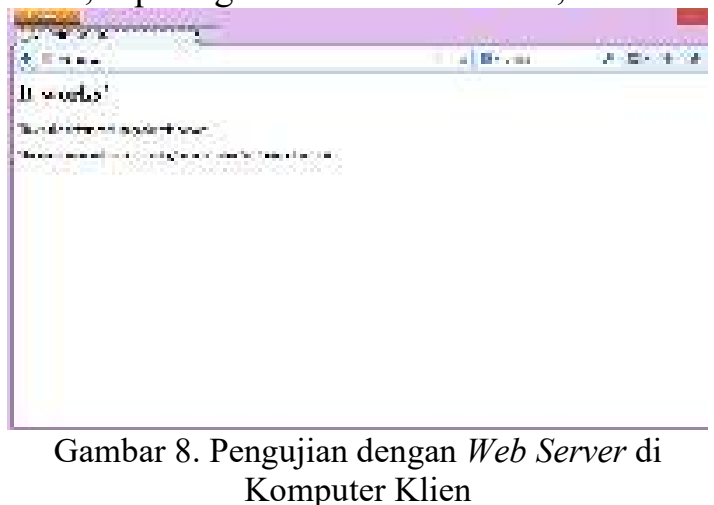

Maka hasil pengujian pertama dengan menggunakan teknik Web Server sudah berhasil dan sistem operasi klien sudah saling berkomunikasi dengan server.

\section{b. Pengujian dengan Samba Server}

Samba adalah program yang bersifat open source yang menyediakan layanan berbagi berkas (file service) dan berbagi alat pencetak (print service), resolusi nama NetBIOS, dan pengumuman layanan (NetBIOS service announcement/browsing). Sebagai sebuah aplikasi file server, Samba mengizinkan berkas, alat pencetak, dan beberapa sumber daya lainnya agar dapat digunakan oleh banyak pengguna dalam keluarga sistem operasi UNIX, dan mengizinkan interoperabilitas dengan sistem operasi Windows.

Samba dibuat berdasarkan protokol Server Message Block (SMB), oleh Andrew
Tridgell. Tahap pertama kali dalam pengujian ini, yaitu instalasi terlebih dahulu keperluan untuk aplikasi Samba Server dengan cara mengetik:

root@debian \# apt-get install samba

Kemudian tentukan berkas mana yang akan saling berbagi dengan komputer klien, yaitu dengan membuat berkas baru atau dengan menggunakan berkas yang telah ada. Misalnya berkas yang akan saling berbagi adalah file "sharing", maka harus dibuat dahulu lokasi, pengguna hak akses, dan kata kunci pada pengguna yang akan dibuat. Dalam konfigurasi Samba Server, poin utama yang harus dirubah adalah pada file smb.conf dengan cara mengetik:

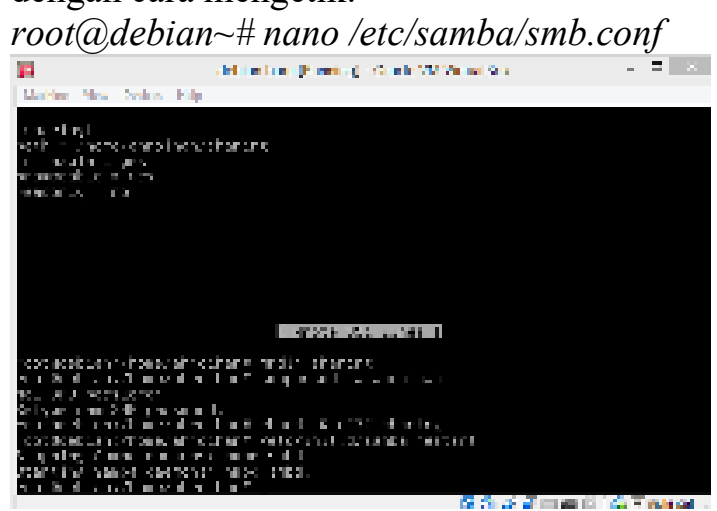

Gambar 9. Konfigurasi Samba Server

Pada gambar 9 menunjukkan bahwa konfigurasi Samba Server di server telah selesai dan siap untuk dilakukan pengujian dengan sistem operasi klien. Pada artikel ini percobaan pengujian dilakukan di klien dengan sistem operasi Windows 8.1,

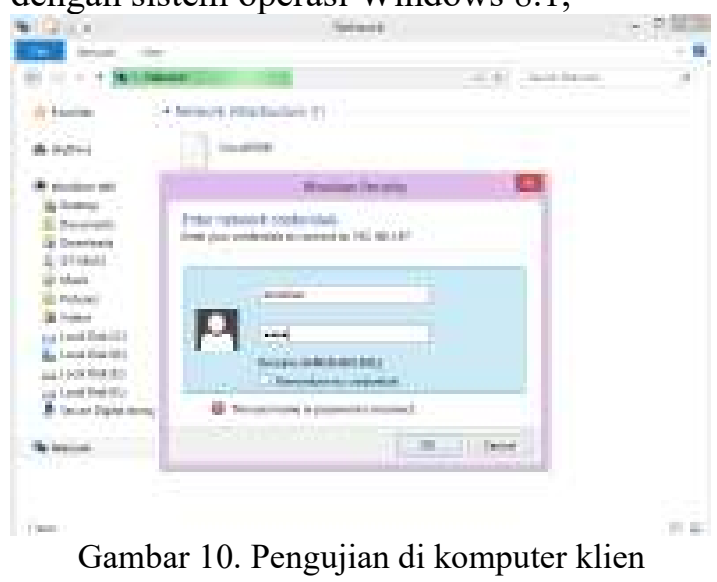

Pengujian di klien telah berhasil dan hak akses pengguna sesuai dengan ketentuan dari konfigurasi sebelumnya, yang mana klien dapat menjelajahi berkas yang telah diberikan yaitu file "sharing", kemudian dapat menambah dan menulis berkas baru di dalam 
file tersebut. Pengujian penambahan dan penulisan berkas baru telah dilakukan pada gambar 11,

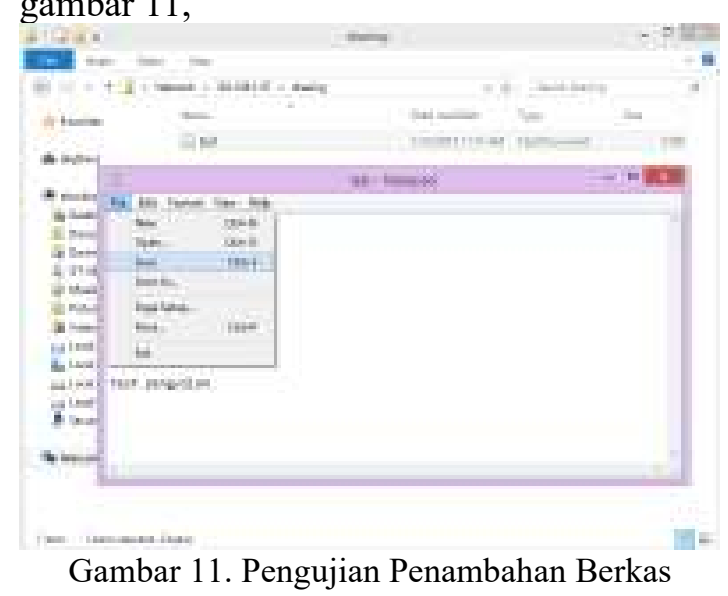

Setelah pengujian di klien telah dilakukan, tahap selanjutnya adalah membuktikan bahwa berkas yang telah ditambahkan telah masuk di server dan dapat disimpan dengan baik.

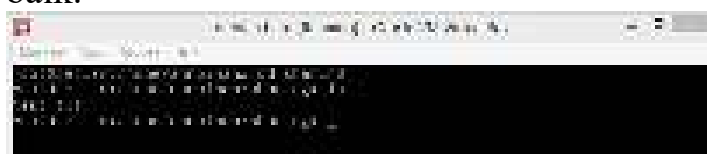

Gambar 12. Pembuktian Berkas di Server

Dengan adanya dua pengujian ini dapat dibuktikan dengan VirtualBox, komunikasi server dan klien tidak hanya terbentur oleh ketersediaan lebih dari satu perangkat komputer saja (hardware), melainkan dengan adanya aplikasi ini dapat membantu untuk mengetahui dan mempelajari bagaimana mengkonfigurasikan sistem operasi yang seharusnya menggunakan dua atau lebih perangkat komputer.

\section{KESIMPULAN}

VirtualBox aplikasi yang sangat membantu dalam memecahkan masalah untuk mempelajari sistem operasi lain seperti server. Hanya dengan satu komputer dapat memiliki lebih dari satu komputer virtual. Oleh karena itu, instalasi lebih dari satu sistem operasi juga dimungkinkan dengan teknik ini. Jika instalasi dan konfigurasi telah dilakukan, maka teknik komunikasi antar sistem operasi dapat diuji dan diterapkan.

\section{SARAN}

Teknik virtualisasi yang dilakukan hanya untuk pembelajaran semata untuk mengetahui instalasi dan konfigurasi sistem operasi di dalam sistem operasi. Untuk mengetahui kinerja server yang sebenarnya disarankan untuk menggunakan minimal dua perangkat komputer, satu komputer berguna sebagai server dan satu yang lainnya sebagai komputer klien. Hal ini berfungsi agar mendapatkan kinerja server yang optimal.

\section{DAFTAR PUSTAKA}

Ladjamudin B, Al-Bahra. 2004. Rekayasa Perangkat Lunak. Yogyakarta: Graha Ilmu.

Mansyurin, Pudja. 2011. Ebook Konfigurasi Debian Server Teknik Komputer dan Jaringan. Mojokerto.

Munif, Abdul. 2013. Sistem Operasi. Malang: Kemdikbud

Novianto, Andi, Kasmadi, Muh, Pramono, Sidik. 2012. Modul Melakukan Instalasi Perangkat Jaringan Lokal (Local Area Network). Jakarta: Erlangga

Pranata, Kadek Surya. 2013. Sistem Operasi Jaringan. Malang: Kemdikbud.

Susilo, Antonius Duty. 2013. Administrasi Server. Malang: Kemdikbud.

http://www.debian.org/. diakses 5 Desember 2014

https://www.samba.org/. diakses 22 Januari 2015

http://www.oracle.com/technetwork/serverstorage/virtualbox/overview/index.htm 1. diakses 17 Nopember 2014

www.samba.org/samba/docs/using_samba/ch 02.html. diakses 3 Januari 2015

http://id.wikipedia.org/wiki/VirtualBox diakses 22 Januari 2015 